\author{
Marquette University \\ e-Publications@Marquette
}

College of Education Faculty Research and

Publications

Education, College of

2012

\title{
Varying Treatment Intensity in a Home-Based Parent and Child Therapy Program for Families Living in Poverty: A Randomized Clinic Trial
}

Robert A. Fox

Marquette University, robert.fox@marquette.edu

Jennifer Carrasco

Marquette University

Follow this and additional works at: https://epublications.marquette.edu/edu_fac

Part of the Education Commons

\section{Recommended Citation}

Fox, Robert A. and Carrasco, Jennifer, "Varying Treatment Intensity in a Home-Based Parent and Child Therapy Program for Families Living in Poverty: A Randomized Clinic Trial" (2012). College of Education Faculty Research and Publications. 213.

https://epublications.marquette.edu/edu_fac/213 
Marquette University

e-Publications@Marquette

\section{Education Faculty Research and Publications/College of Education}

This paper is NOT THE PUBLISHED VERSION; but the author's final, peer-reviewed manuscript. The published version may be accessed by following the link in the citation below.

Journal of Community Psychology, Vol. 40, No. 5 (July 2012): 621-630. DOI. This article is (c) Wiley and permission has been granted for this version to appear in e-Publications@Marquette. Wiley does not grant permission for this article to be further copied/distributed or hosted elsewhere without the express permission from Wiley.

\section{Varying Treatment Intensity in A Home-Based Parent and Child Therapy Program for Families Living in Poverty: A Randomized Clinic Trial}

Jennifer M. Carrasco

Department of Education, Marquette University, Milwaukee, WI

Robert A. Fox

Department of Education, Marquette University, Milwaukee, WI

\section{Abstract}

This study addressed the question of whether increasing the intensity of a parent and child therapy program would improve results for young children with significant behavior problems from families living in poverty. Children were randomly assigned to either a standard condition or an intensity condition that provided $50 \%$ more treatment over a standard 8-week treatment period. Based on multiple parent-report, direct observation, and clinician-report measures of the children and their caregivers, both groups improved on all measures from 
pretest to posttest and from pretest to follow-up. No differences in outcomes were found between the standard and intensity groups at posttest or follow-up. These counterintuitive results are discussed within the parent and child intervention literature. Also, the heuristic potential of this study to encourage continued research with this challenging population is addressed.

Given the poor developmental pathway for young children with serious behavior problems, there has been growing recognition that early intervention is a critical step in preventing long-term negative outcomes (Innocenti \& White, 1993). Research shows that participation in parent and child therapy (PCT) programs significantly reduces childhood behavior problems and harsh parenting techniques while increasing positive parenting (Eyberg, Nelson, \& Boggs, 2008). However, there is evidence that some children do not make expected gains or complete treatment (Kazdin, Holland, \& Crowley, 1997). Research shows that $40 \%$ to $60 \%$ of families who begin treatment for their children terminate prematurely (Kazdin, 1996) and that individuals from low-income populations are at an increased risk for dropping out of therapy (Fox \& Holtz, 2009). Research on implementing PCT programs with some of the most at-risk children is severely limited. Specifically, the level of treatment intensity (i.e., the number, frequency, and regularity of sessions) is believed to play an important role in treatment (Webster-Stratton \& Hammond, 1997), yet there is a dearth of studies that examine treatment intensity in the context of PCT programs. There is evidence that families who attend more sessions (greater than $50 \%)$ have better outcomes than families with poor attendance (Strain, Steele, Ellis, \& Timm, 1982).

The purpose of this study was to investigate the effect of varying the level of treatment intensity on outcomes in a PCT program for low-income children aged 5 years and younger with externalizing behavior problems, the majority of whom also had a developmental disability. Participants were randomly assigned to one of two groups: a standard treatment that included eight treatment sessions in 8 weeks or an intensity treatment that included $50 \%$ more treatment sessions in 8 weeks.

\section{METHOD}

The following sections obtain a description of the five eligibility criteria for participation in this study and the demographic data for the children and their families. Also included is a description of the evidence-based treatment program and the multiple measures used to assess treatment outcomes.

\section{Participants}

The participants in this study were children from a large, urban Midwestern city referred to a clinic developed specifically to address mental health issues in very young children (Fox, Keller, Grede, \& Bartosz (2007). Eligibility criteria for the study are as follows: (a) the child was 5 years of age or younger; (b) the child met or exceeded the cutoff score for clinical significance on the Intensity Scale of the Eyberg Child Behavior Inventory ( $t$ score $\geq$ 60; Eyberg \& Pincus, 1999); (c) the child did not have significant physical disabilities, serious medical conditions, or present with a pervasive developmental disorder (PDD); (d) the child's family was below the federal poverty level; and (e) the child's parent/guardian signed an institutional review board-approved consent form. Using a computer-generated random numbers table, eligible children were randomly assigned to one of two treatment levels: standard or intensity treatment. When children and their primary caregiver attended all treatment sessions based on their group assignment (i.e., eight sessions for the standard group and 12 sessions for the intensity group) and completed the additional three assessment sessions (i.e., pretest, posttest, and 4-6-week follow-up), they were entered into the final sample pool until a total of 60 children (30 per group) was reached.

\section{Procedures}

All treatment services and data collection occurred in the children's homes. An initial, 2-hour intake session was conducted that included a review of available records and a comprehensive parent interview to determine the history and current factors that contributed to the child's referral concern. In addition, parent-child interactions 
were rated during a play period, rates of children's compliance to parent requests were recorded, and the study's parent-report measures were completed. The first treatment session was scheduled to occur within a week of the intake. This study utilized an individualized format of the Parenting Young Children Program (PYC) for young children (Fox \& Nicholson, 2003).

The PYC Program includes four main treatment elements: (a) strengthening the parent/child relationship through nondirective play and increased child nurturing activities; (b) helping parents to learn and maintain appropriate developmental expectations for their child and to learn cognitive strategies to avoid emotionally overreacting to their child's challenging behavior in a negative manner; (c) using techniques to strengthen the child's prosocial behaviors such as positive reinforcement, establishing home routines, and giving good instructions; and (d) employing limit-setting strategies to reduce the child's challenging behaviors such as redirection, ignoring, response cost, and time-out. The clinician explained treatment strategies to the parent and directly modeled them. Parents also practiced each strategy with their children during the treatment sessions and received immediate feedback from the clinician. Handouts, and other materials needed to implement the treatment, were provided, which explained the treatment strategies in more detail (e.g., edible reinforcers, stickers, door gates for time-out, safety latches for doors).

Based on the study's design, families in the intensity treatment group were scheduled to receive $50 \%$ more treatment time than families in the standard treatment group over an 8-week treatment period. Time-intreatment was defined as the number of weeks taken to complete the required treatment sessions. A statistical analysis showed no differences in time-in-treatment between the standard and intensity groups ( $p>.05$; see Table 1). Clinicians were master's-degreed professional counselors and graduate students. Training included didactic instruction based on a comprehensive training manual, viewing treatment program videotapes and rating parent-child interactions to ensure inter-rater reliability, shadowing treatment sessions, and a gradual assumption of the role of clinician in the field under close supervision.

Table 1. Demographic Data for Standard Treatment and Intensity Treatment Groups at Intake

\begin{tabular}{|l|l|l|l|l|l|l|l|l|}
\hline & Standard treatment & & & & Intensity treatment & & & \\
\hline Variable & $\boldsymbol{M}$ & SD & $\boldsymbol{n}$ & $\mathbf{\%}$ & $\boldsymbol{M}$ & SD & $\boldsymbol{n}$ & $\%$ \\
\hline Age of child & 2.49 & .70 & 30 & 100 & 2.72 & .65 & 30 & 100 \\
\hline Gender & & & & & & & & \\
\hline Female & & & 9 & 30 & & & 9 & 30 \\
\hline Male & & & 21 & 70 & & & 21 & 70 \\
\hline Race & & & & & & & & \\
\hline African American & & & 21 & 70 & & & 15 & 50 \\
\hline Latino & & & 3 & 10 & & & 7 & 23 \\
\hline Caucasian & & & 3 & 10 & & & 3 & 10 \\
\hline Mixed ethnicity & & & 3 & 10 & & & 5 & 17 \\
\hline Psychiatric diagnosis & & & 27 & 90 & & & 28 & 93 \\
\hline Developmental delay & & & 18 & 60 & & & 19 & 63 \\
\hline Maternal marital status & & & & & & & \\
\hline Married & & & 6 & 20 & & & 7 & 23 \\
\hline Not married & & & 24 & 80 & & & 23 & 77 \\
\hline Years of parent education & 12.3 & 1.98 & & & 12.1 & 1.90 & & \\
\hline Age of parent & 28.5 & 8.1 & & & 31.9 & 12.9 & & \\
\hline Weeks in treatment & 8.9 & 1.3 & & & 8.7 & 1.9 & & \\
\hline Attendance (\%) & 87.3 & 12.2 & & & 84.1 & 10.5 & & \\
\hline
\end{tabular}

Note $\mathrm{M}=$ mean; $\mathrm{SD}=$ standard deviation. 
Fidelity to the treatment program was established through the use of specific treatment adherence criteria that were met by all therapists and students prior to their functioning independently as a clinician to ensure consistent administration of the treatment program. Each clinician also participated in ongoing weekly supervision (group and individual) to receive assistance on specific issues that arose with families and for feedback on their performance while implementing the treatment program.

\section{Measures}

The Eyberg Child Behavior Inventory (ECBI; Eyberg \& Pincus, 1999) is a 36-item inventory that measures common behavior problems in children between the ages of 2 and 16 years. A $t$ score of 60 has been established as the cutoff score for clinical significance. Evidence of reliability of the ECBI for the intensity and problem scales, respectively, included coefficient alphas $(.95, .93)$, test-retest $(.80, .85)$ and inter-rater $(.86, .79)$.

The Parent Behavior Checklist (PBC; Fox, 1994) is a 32-item rating scale that was designed to measure the behaviors and expectations of parents of young children. The PBC comprises three scales: Expectations -12 items that measure parents' developmental expectations; Discipline -10 items that assess parental responses to children's problem behaviors; and Nurturing-10 items that measure specific parent behaviors that promote a child's psychological growth (e.g., "My child and I play together on the floor"). Reliability of the PBC for the Expectations, Discipline, and Nurturing scales, respectively, included coefficient alphas $(.97, .91, .82)$ and testretest $(.98, .87, .81)$.

Parents were instructed to play with their child with a standard set of toys while the clinician observed and rated the quality of the parent and child interaction. Based on the work of Crawley and Spiker (1983), five dimensions of the child's behavior and six dimensions of the parent's behavior were rated using a five-point frequency scale, ranging from 1 (never) to 5 (always). Separate total scores were computed for the five dimensions of the child's behaviors and the six dimensions of the parent's behaviors. Coefficient alphas for the sample were computed for the child behavior score (.82) and the parent behavior score (.78).

After the direct observation of the parent-child interactions, parents were told to give their child five standard requests to allow the clinician to assess how well their child listened to them (e.g., pick up the toy, come here). The percentage of time the child complied with parental requests was computed (number of complies/number of requests X 100) and this percentage score was used for subsequent analyses. Inter-rater reliability was $96 \%$ for parents' requests and $100 \%$ for the children's compliance.

The Kiddie Schedule for Affective Disorders and Schizophrenia for School-Aged Children (K-SADS-PL; Kaufman et al., 1997) is a semistructured parent interview designed to assess current episodes of psychopathology in children. The K-SADS-PL comprises separate screens and supplemental diagnostic assessments for each psychiatric disorder appropriate for children included in the Diagnostic and Statistical Manual of Mental Disorders (DSM-IV-TR; APA, 2000). Birmaher et al. (2009) used the K-SADS-PL with a sample of 2-5-year-old children and reported strong inter-rater reliability (Kappas .80-.90) and good evidence of convergent, divergent, and predictive validity. The Parent-Child Relationship Scale (Fox \& Nicholson, 2003) provides a quantitative global assessment of the parent and child relationship on a scale of 0-100 with five behavioral anchors (Poor, Below Average, Average, Good, and Exceptional) at 20-point intervals. Finally, the Family Satisfaction Survey (Fox \& Holtz, 2009), a 7-item survey, was used to assess caregiver satisfaction with the treatment services.

\section{RESULTS}

Table 1 shows the demographic data for the participants by treatment group. Of the 30 children in the standard treatment group, 26 (87\%) met criteria for a psychiatric diagnosis at intake with oppositional defiant disorder being the most prevalent diagnosis $(n=23 ; 88 \%)$. The majority of the children $(n=18 ; 60 \%)$ also were identified 
as having one or more developmental delays. In the intensity group, 28 children (93\%) met criteria for a psychiatric diagnosis at intake and oppositional defiant disorder was again the most frequent diagnosis $(n=26$; $93 \%)$. The majority of these children $(n=19 ; 63 \%)$ also were identified as having one or more developmental delays. Parents were asked to identify their main referral concern; 26 parents (87\%) in both groups identified externalizing behaviors (e.g., oppositional behavior, temper tantrums, aggression) as their primary concern. No differences in length of time-in-treatment were found between the standard and intensity groups; also the attendance rate for treatment sessions was similar between groups (see Table 1).

The means and standard deviations for each dependent measure obtained at pretest, posttest, and follow-up for the standard and intensity groups are shown in Table 2. To answer the primary research question-Do the standard and intensity groups change differently from pretest to posttest? -a series of analysis of covariance (ANCOVAs) were computed for the dependent variables to analyze the posttreatment scores with the pretest scores held constant. A second series of ANCOVAs were computed to analyze the follow-up scores with the pretest scores held constant. Finally, to assess the effect size of the treatment program from pretest to posttest and from pretest to follow-up, Cohen's $d$ (Cohen, 1988) was computed for each dependent variable. Effect sizes were classified as follows: $.2=$ small, $.5=$ moderate and $.8=$ large. 
Table 2. Means and Standard Deviation Scores by Standard and Intensity Groups

\begin{tabular}{|c|c|c|c|c|c|c|c|c|c|c|c|c|c|c|c|c|}
\hline & $\begin{array}{l}\text { Standard } \\
\text { treatment } \\
(\mathrm{n}=30)\end{array}$ & & & & & & & & $\begin{array}{l}\text { Intensity } \\
\text { treatment } \\
(\mathrm{n}=30)\end{array}$ & & & & & & & \\
\hline & Pretest & & Posttest & & & $\begin{array}{l}\text { Follow- } \\
\text { up }\end{array}$ & & & Pretest & & Posttest & & & Follow-up & & \\
\hline Measure & $M$ & SD & $M$ & SD & $d^{a}$ & $M$ & SD & $d^{b}$ & $M$ & SD & $\mathbf{M}$ & SD & $d^{a}$ & $\mathbf{M}$ & SD & $d^{b}$ \\
\hline \multicolumn{17}{|l|}{ ECBI } \\
\hline Intensity & 172.53 & 27.30 & 138.77 & 40.28 & 0.98 & 144.57 & 47.29 & 0.72 & 168.43 & 21.80 & 135.77 & 43.50 & 0.95 & 136.53 & 43.58 & 0.93 \\
\hline Problem & 22.63 & 5.94 & 15.30 & 9.98 & 0.89 & 15.57 & 10.81 & 0.81 & 23.33 & 7.04 & 16.80 & 10.63 & 0.72 & 15.53 & 11.53 & 0.82 \\
\hline \multicolumn{17}{|l|}{ PBC } \\
\hline Expectations & 30.70 & 7.95 & 32.93 & 9.02 & 0.26 & 33.70 & 7.72 & 0.38 & 29.87 & 7.28 & 31.50 & 6.72 & 0.23 & 33.37 & 6.84 & 0.50 \\
\hline Discipline & 15.17 & 4.59 & 13.37 & 3.75 & 0.43 & 14.37 & 4.41 & 0.18 & 14.40 & 3.55 & 12.57 & 2.66 & 0.58 & 12.67 & 2.89 & 0.54 \\
\hline Nurturing & 29.97 & 5.36 & 31.57 & 5.29 & 0.30 & 31.83 & 4.95 & 0.37 & 28.10 & 5.77 & 30.77 & 4.16 & 0.53 & 30.37 & 5.13 & 0.42 \\
\hline \multicolumn{17}{|l|}{$\begin{array}{l}\text { Parent-child } \\
\text { interactions }\end{array}$} \\
\hline $\begin{array}{l}\text { Child } \\
\text { behavior }\end{array}$ & 17.47 & 3.99 & 20.47 & 2.35 & 0.92 & 20.40 & 2.43 & 0.89 & 17.90 & 3.26 & 21.10 & 2.62 & 1.08 & 20.70 & 2.65 & 0.94 \\
\hline $\begin{array}{l}\text { Parent } \\
\text { behavior }\end{array}$ & 18.93 & 3.79 & 23.67 & 2.64 & 1.45 & 22.63 & 2.92 & 1.09 & 18.77 & 3.33 & 23.77 & 3.15 & 1.54 & 23.43 & 3.70 & 1.32 \\
\hline $\begin{array}{l}\text { Compliance } \\
(\%)\end{array}$ & 32.79 & 24.71 & 57.60 & 22.65 & 1.05 & 65.30 & 29.19 & 1.20 & 36.77 & 31.99 & 55.07 & 31.09 & 0.58 & 64.10 & 30.24 & 0.88 \\
\hline $\begin{array}{l}\text { Parent-child } \\
\text { relationship }\end{array}$ & 53.50 & 10.92 & 74.50 & 10.78 & 0.94 & 73.50 & 14.03 & 1.59 & 53.83 & 10.80 & 72.67 & 12.16 & 1.64 & 70.33 & 13.64 & 1.34 \\
\hline
\end{tabular}

Note $\mathrm{M}=$ mean; $\mathrm{SD}=$ standard deviation; $d^{a}=$ pretest to posttest effect size comparison; $d^{b}=$ pretest to follow-up effect size comparison; $\mathrm{ECB}=$ Eyberg

Child Behavior Inventory; PBC = Parent Behavior Checklist. 
Both the standard and the intensity groups showed large gains ( $d=.95$ to .98 ) from pretest to posttest on the ECBI's intensity scores, indicating that the severity of the children's behavior problems had reduced following the treatment program. The gains at follow-up were moderate for the standard group but remained large for the intensity group. The standard and intensity groups showed moderate to large gains ( $d=.72$ to .89 ) from pretest to posttest on the ECBI's problem scores, indicating that the problematic nature of the children's behavior had reduced following the treatment program. The gains at follow-up were large for both the standard and the intensity groups. The results of the separate ANCOVAs for the ECBI's intensity and problem scores by treatment group at posttest and follow-up were not significant, suggesting there were no differences between the standard and intensity group on these scores.

Both the standard and the intensity groups showed small gains ( $d=.23$ to .26 ) from pretest to posttest on the PBC's expectations scores, indicating a slight increase in parent expectations following the treatment program. The gains at follow-up were small for the standard group and moderate for the intensity group. The standard group and intensity groups showed small to moderate gains ( $d=.43$ to .58 ) from pretest to posttest on the PBC's discipline scores, indicating that parents were using less corporal and verbal punishment as a form of discipline with their children after the treatment program. The gains at follow-up were insubstantial for the standard group but remained moderate for the intensity group. The standard and intensity groups showed small to moderate gains ( $d=.30$ to .53 ) from pretest to posttest on the PBC's nurturing scores, indicating that parents were using more positive nurturing strategies with their children following the treatment program. The gains at follow-up were small for both the standard and the intensity groups. The results of the separate ANCOVAs for the PBC's scores were not significant.

Both the standard and the intensity groups showed large gains ( $d=.92$ to 1.08 ) from pretest to posttest on the child behavior scores during play, indicating an improvement in the children's interactions with their parents following the treatment program. The gains at follow-up remained large for both the standard and the intensity groups, which showed large gains $(d=1.45-1.54)$ from pretest to posttest on the parent behavior scores during play, indicating an improvement in the parent's interactions with their children following the treatment program. The gains at follow-up remained large for both the standard and the intensity groups. Both the standard and the intensity groups showed moderate to large gains ( $d=.58$ to 1.05$)$ from pretest to posttest on the child compliance scores, indicating that the children had improved their compliance to parent requests following the treatment program. The gains at follow-up were large for both the standard and the intensity groups, which showed large gains ( $d=.94$ to 1.64) from pretest to posttest on the PCRS, indicating an improvement in the quality of the parent-child relationship following the treatment program. The gains at follow-up remained large for both the standard and the intensity groups. The results of the separate ANCOVAs for the child and parent behavior scores, the child's compliance scores, and the PCRS by treatment group at posttest and follow-up were not significant.

\section{Clinical significance and treatment satisfaction}

At intake, 30 children in each treatment group met or exceeded the cutoff score for clinical significance on the ECBI's intensity scale $(t=60)$, which was one of the eligibility criteria for this study. At posttest, 13 children in the standard group (43\%) and 16 children in the intensity group (53\%) no longer met this cutoff score; at follow-up, no changes occurred in the standard group but three children in the intensity group now met the cutoff score. At intake, 29 children in the standard treatment group and 27 in the intensity group met or exceeded the cutoff score for clinical significance on the ECBI's problem scale $(t=60)$. At posttest, 13 children in the standard group (43\%) and 14 children in the intensity group (47\%) no longer met this cutoff score; at follow-up, two additional children in the standard group and one additional child in the intensity group no longer met the cutoff score. At intake, 26 children in the standard treatment group and 28 children in the intensity treatment group met the criteria for a DSM-IV TR Axis I diagnosis with oppositional defiant disorder being the most common. At 
posttreatment, of the children with a psychiatric diagnosis at intake, 16 in the standard group (62\%) and 17 children in the intensity group (61\%) no longer met the criteria for a diagnosis; these results were maintained at follow-up for both groups. The average scores on the family satisfaction measure were 42.8 (standard deviation $[S D]=5.1)$ for the standard group and $44.3(S D=4.0)$ for the intensity group; these total scores for the two groups did not differ significantly from each other.

\section{DISCUSSION}

This study was the first known attempt to use treatment intensity as the independent variable in an effort to understand its role in outcomes for families living in poverty with very young children with significant behavior problems. Results indicated that group classification (i.e., standard or intensity) did not differentially affect child or parent outcomes at posttest or follow-up. Regardless of their level of treatment intensity, children and caregivers demonstrated treatment gains on nearly all of dependent measures from pretest to posttest and from pretest to follow-up. One explanation for the lack of significant differences across groups is that time-intreatment may not be a critical mechanism of change in PCT therapy.

In the present study, there were parents that quickly learned and implemented treatment techniques and who observed evidence of their success through positive changes in their children's behavior, some in as short as 4 weeks. There were other parents that needed more time to learn the same strategies, implement them successfully, and witness their positive effects on their children's behavior. The findings from this study suggest that most parents can acquire skills that result in positive outcomes in 8 weekly treatment sessions. Other studies have documented that PCT programs providing less treatment time have similar positive effects (Nixon, Sweeney, Erickson, \& Touyz, 2003). Therefore, rather than focusing on establishing any one particular treatment time period for the implementation of PCT programs, what may be more critical is that PCT programs have flexible treatment schedules that accommodate the individualized nature of learning and the unique family barriers that may affect their participation in treatment (e.g., lack of transportation or child care; child illness). Also, based on the present findings, practitioners who offer PCT programs with families within the traditional weekly appointment framework should be reassured that this level of treatment intensity can produce the desired outcomes.

The present study found that over $60 \%$ of eligible children did not complete treatment based on a very conservative definition of program completion (i.e., attend all treatment and evaluation sessions including a 4-6week follow-up evaluation). Recently, Fernandez, Butler, and Eyberg (2011) reported a similarly high attrition rate of 56\% and Fox and Holtz (2009) reported a 57\% drop-out rate, both for low-income samples of families. In the present study, families who completed the entire program did not differ from noncompleters on any of the demographic variables shown in Table 1. Noncompleters assigned to the standard group tended to drop out of treatment sooner ( $58 \%$ by third session) than noncompleters in the intensity group ( $34 \%$ by third session); attendance rates between these two groups did not differ (standard $=58 \%$, intensity $=65 \%$ ).

One of the major challenges in this study was controlling the independent variable. The sample comprised children and caregivers whose demographic characteristics (i.e., low income, less educated, single-parent households, majority of children with developmental delays) placed them at high-risk for poor treatment adherence. It took our clinic 2 full years to meet all of the study's parameters even with only 30 participants needed in each of the two treatment groups. This population of at-risk children and their families clearly are in need of new research-guided, treatment services within a community-based model. However, the inherent treatment engagement and research challenges encountered when studying these families requires a level of time and commitment that will continue to slow our progress in addressing their needs in the most effective way. 
The results from the present study suggests that attempting to fit low-income families of children with behavior problems into a standard PCT format may not be advised. Based on our experiences, we have adapted our program in two ways: first, we have front-loaded much of the content and strategies into the first few sessions with the remaining sessions concentrating on problem solving with families over implementation issues that may arise (e.g., how to do a time-out in a very small living space with several occupants); and second, when a child reaches the treatment goals established by the family and the clinician, we terminate treatment independent of the time needed to achieve these goals.

This study also has heuristic value by encouraging more researchers to include young children from low-income families in their work. Although this clearly is a challenging population, the need is apparent and the treatment outcomes, while not as significant as those reported for middle to upper income families, do improve the quality of life for those families and their children who do experience treatment success. Also, there remains a need to not only tailor treatment programs to each family, but also to more sensitively assess positive changes that may be occurring during treatment rather than limiting our evaluations to a pre, post, follow-up design. Currently, we are conducting treatment outcome assessments as part of each treatment session to more accurately assess change over the course of treatment.

\section{REFERENCES}

American Psychological Association. (2000). Diagnostic and statistical manual of mental disorders (4th ed. text revision). Washington, DC: Author.

Birmaher, B., Ehmann, M., Axelson, D. A., Goldstein, B. I., Monk, K., Kalas, R. N., ... Brent, D. A. (2009). Schedule for Affective Disorders and Schizophrenia for School-Age Children (K-SADS-PL) for the assessment of preschool children - A preliminary psychometric study. Journal of Psychiatric Research, 43, 680-686.

Cohen, J. (1988). Statistical power analysis for the behavioral sciences ( 2nd ed.). Hillsdale, NJ: Lawrence Earlbaum Associates.

Crawley, S.B., \& Spiker, D. (1983). Mother-child interactions involving two-year-olds with Down syndrome: A look at individual differences. Child Development, 54, 1312- 1323.

Eyberg, S.M, Nelson, M. M., \& Boggs, S. R. (2008). Evidenced-based psychosocial treatments for children and adolescents with disruptive behavior. Journal of Clinical Child and Adolescent Psychology, 37, 215- 237.

Eyberg, S.M., \& Pincus, D. (1999). Eyberg Child Behavior Inventory and Sutter-Eyberg Student Behavior InventoryRevised: Professional manual. Lutz, Florida: Psychological Assessment Resources, Inc.

Fernandez, M. A., Butler, A. M., \& Eyberg, S. M. (2011). Treatment outcome for low socioeconomic status African American Families in Parent-Child Interaction Therapy: A pilot study. Child \& Family Behavior Therapy, 33, 32- 48.

Fox, R.A. (1994). Parent behavior checklist. Austin, TX: ProEd (Currently available from the author: Marquette University, School of Education, P.O. Box 1881, Milwaukee, WI 53201-1881; Email: robert.Author@marquette.edu).

Fox, R.A., \& Holtz, C. A. (2009). Treatment outcomes for toddlers with behavior problems from families in poverty. Child and Adolescent Mental Health, 14, 183- 189.

Fox, R., Keller, K. M., Grede, P. L., \& Bartosz, A. M. (2007). A mental health clinic for toddlers with developmental delays and behavior problems. Research in Developmental Disabilities, 28, 119- 129.

Fox, R.A., \& Nicholson, B. (2003). Parenting Young Children: A facilitator's guide. Longmont, CO: Sopris West.

Innocenti, M. S., \& White, K. R. (1993). Are more intensive early intervention programs more effective? A review of the literature. Exceptionality, 4, 31- 50.

Kaufman, J., Birmaher, B., Brent, D., Rao, U., Ryan, N., Flynn, C., \& Moreci, P. (1997). The Revised Schedule for Affective Disorders and Schizophrenia for School Aged Children: Present and Lifetime Version: Preliminary reliability and validity data. Journal of the American Academy of Child and Adolescent Psychiatry, 36, 980-988. 
Kazdin, A. E. (1996). Dropping out of child therapy: Issues for research and implications for practice. Clinical Child Psychology and Psychiatry, 1, 133-156.

Kazdin, A. E., Holland, L., \& Crowley, M. (1997). Family experience of barriers to treatment and premature termination from child therapy. Journal of Consulting and Clinical Psychology, 65, 453- 463.

Nixon, R. D, Sweeney, L., Erickson, D. B., \& Touyz, S. W. (2003). Parent-child interaction therapy: A comparison of standard abbreviated treatments for oppositional defiant preschoolers. Journal of Consulting and Clinical Psychology, 71, 251- 260.

Strain, P., Steele, P., Ellis, T., \& Timm, M. (1982). Long-term effects of oppositional child treatment with mothers as therapists and therapist trainers. Journal of Applied Behavior Analysis, 15, 163-169.

Webster-Stratton, C., \& Hammond, M. (1997). Treating children with early-onset conduct problems: A comparison of child and parent training interventions. Journal of Consulting and Clinical Psychology, 65, 93- 109. 